\title{
CONCEPÇÕES DE SAÚDE E DOENÇA MENTAL PARA PROFISSIONAIS DE UM CAPSI
}

\author{
Camila Carlos Maia ${ }^{1}$ \\ Prefeitura Municipal de Serra-ES, Brasil \\ Luziane Zacché Avellar \\ Universidade Federal do Espírito Santo, Vitória-ES, Brasil
}

\begin{abstract}
RESUMO. A implantação de dispositivos destinados exclusivamente ao atendimento de crianças e de adolescentes com transtornos mentais graves é uma conquista recente, por isso são poucos os estudos que enfoquem estes serviços. Nesta pesquisa, tivemos como objetivo investigar como os profissionais que atuam em um Centro de Atenção Psicossocial Infanto-juvenil (CAPSi) de uma cidade da Região Sudeste do Brasil concebem os processos de saúde e doença dos usuários deste serviço. Entrevistamos vinte e quatro profissionais, mediante um roteiro semiestruturado. Os dados foram submetidos a uma análise de conteúdo temática. Destacaram-se entre os temas de análise: a explicação de transtornos mentais sob uma ótica pluricausal; a menção do transtorno como um fenômeno relacional; a abertura à cidadania e à reinserção social; a presença do sofrimento psíquico e de oscilações no transtorno; e a importância de detectar precocemente tais situações. As ideias que circulam entre o profissionais parecem considerar as particularidades do público atendido, com uma inclinação terapêutica aliada às políticas destinadas a este público.
\end{abstract}

Palavras-chave: Serviços de saúde mental; crianças; adolescentes.

\section{CONCEPTIONS OF HEALTH AND MENTAL DISEASE TO PROFESSIONALS IN A CAPSI}

\begin{abstract}
The establishment of mechanisms used exclusively to the assistance of children and adolescents with severe mental disorders is a recent achievement. Therefore, there are few studies focusing these services. This research aims at investigating the way the professionals who work at a Psychosocial Community Care Center for Children and Adolescents (CAPSi) from a city in the southeast of Brazil understand the processes of health and illness of the users of this service. 24 professionals were interviewed. We used semi-structured guided questions. The data were submitted to a theme-content analysis. Among the themes of analysis we pointed out: the explanation of mental diseases under a multi-causal view; the fact that the disorder is understood as a related phenomenon; the possibility of social reintegration and citizenship; the presence of psycho-suffering and the variations in the disorder; the importance of early diagnosis for such cases. The professionals involved seem to be concerned to the peculiarity of the users, with a therapeutic tendency associated to the policies addressed to those people.
\end{abstract}

Key words: Mental health services; children; adolescents.

\section{CONCEPCIONES DE SALUD Y ENFERMEDAD MENTAL PARA PROFESIONALES DE UN CAPSI}

RESUMEN. El establecimiento de dispositivos dedicados exclusivamente a los niños y jóvenes con enfermedades mentales graves es un logro reciente, y existen pocos estudios centrándose en estos servicios. Nuestro objetivo es investigar como los profesionales que trabajan en un Centro de Atención Psicosocial para Niños y Jóvenes (CAPSi) de una ciudad en el sureste de Brasil comprenden los procesos de salud y enfermedad de los usuarios de este servicio. 24 profesionales fueron entrevistados, con un guión de preguntas semiestructuradas. Los datos fueron sometidos a un análisis de contenido temático. Algunos de los temas más destacados: las múltiples causalidades para las enfermedades mentales; la enfermedad como un fenómeno

1 Endereço para correspondência: Av. Fernando Ferrari, 514, Goiabeiras - CEP 29.075-910, Vitória-ES, Brasil. Email: milamaia.vix@terra.com.br 
relacional; la posibilidad de reinserción social y de ciudadanía; la presencia de sufrimiento psíquico y sus altibajos; la importancia del diagnóstico precoz. Las ideas que circulan entre los profesionales parecen considerar las peculiaridades de los usuarios, con una tendencia terapéutica vinculada a las políticas que se aplican a los mismos.

Palabras-clave: Servicios de salud mental; niños; adolescentes.

A partir das deliberações da III Conferência Nacional de Saúde Mental, em 2002, o Ministério da Saúde baixou a Portaria n. 336/ GM, de 2002, em que os Centros de Atenção Psicossocial Infanto-juvenil (CAPSi's) são normatizados como serviços ambulatoriais de atenção diária, territorializados e de natureza pública para crianças e adolescentes. Assim como as outras modalidades de CAPS, os CAPSi's são planejados para prestar atendimento a pacientes com transtornos mentais graves na área territorial em que se localizam, oferecendo tratamento intensivo, semi-intensivo e não intensivo.

Uma questão que acompanha o surgimento de tais dispositivos diz respeito à postura assumida pelos profissionais de saúde mental diante das demandas que se lhes apresentam nos serviços. Algumas vezes a criança e o adolescente são tomados como objetos do discurso e da prática de diversos setores sociais que tomam o seu comportamento "irregular" como anormal do ponto de vista de um ideal psicológico forjado socialmente, trazendo consequências ideológicas de massificação, homogeneização e finalmente, de segregação da singularidade, representada por este comportamento (Akerman, 2003, pp. 199-200).

Reconhecer a presença da segregação da criança e do adolescente nos discursos dos mais variados setores sociais é fundamental para podermos apreender o que muitas vezes se espera dos serviços de assistência em saúde mental a crianças e adolescentes. Como mostra Akerman (2003), o discurso da ordem que permeia os setores em questão está atravessado pela ideologia liberal, que convida à eficiência, ao êxito, e à produtividade, marcando a fronteira entre o aceitável e o inaceitável, o normal e o patológico.

Saraceno (2001) enfatiza a existência de um viés ideológico nos diagnósticos de transtornos mentais que busca excluir os portadores desses transtornos. Estariam os profissionais sendo cúmplices desta lógica? Como delimitar as fronteiras entre o normal e o patológico, em especial quando se trata de crianças e adolescentes, em que os desafios de sistematização de conhecimentos se ampliam (Couto, Duarte \& Delgado, 2008)?

Para o filósofo francês Canguilhem (1943), não é possível conceber um estado patológico em si, haja vista o caráter relacional de todo e qualquer adoecimento. Uma patologia é sempre reconhecida enquanto tal a partir de um determinado contexto. Se retomarmos as colocações de Akerman (2003) acerca das práticas e discursos de segregação delineados em relação ao público infanto-juvenil, veremos que um comportamento muitas vezes ganha o rótulo de "patológico" a depender da ideologia que atravessa a prática profissional.

Para Coelho e Almeida Filho (2002), abordar o tema saúde positivamente tem se mostrado desafiador, talvez pela pouca presença de estudos que delimitem o que é saúde. Então, como definir o que é ou não saudável dentro do entremeado campo da saúde mental infantojuvenil?

Diante da necessidade constante de problematização, mostra-se importante conhecer as concepções dos profissionais do CAPSi sobre os processos de saúde e doença mental de crianças e adolescentes que chegam ao serviço. $\mathrm{O}$ que pensam os profissionais do CAPSi sobre as crianças que buscam o serviço? Como entendem o que elas apresentam? Existem critérios que delimitam quem deve ou não ser incluso nas atividades do CAPSi?

Por meio de uma abordagem histórica da infância, Boarini e Borges (1998) refletem sobre a alta demanda por serviços de saúde mental infantil no Brasil, partindo do pressuposto de que a maior parte da procura por esses serviços provém de membros das classes populares. As autoras afirmam que muitos dos encaminhamentos trazem em si uma visão preconceituosa, seja dos pais e professores, seja do próprio profissional de saúde mental. Este, com seu olhar estigmatizante, acaba por reeditar o surgimento de novos problemas além da queixa tal qual ela se apresenta.

Bastos (2003) teve como um de seus objetivos apreender as concepções de criança e 
adolescente emergidas dos discursos de gestores e profissionais atuantes na área da atenção básica. Apareceu entre as representações discursivas a concepção de sujeito indefeso e desprovido de cidadania, sendo que algumas das visões "remetem genericamente à questão dos Direitos Sociais." (Bastos, 2003, p. 91).

Em um município de médio porte do Interior do Estado de São Paulo, profissionais integrantes de uma equipe de Saúde da Família expressam compreender o sofrimento psíquico a partir de "uma abordagem ampliada do processo saúde-doença, incluindo dimensões psicossociais e os determinantes da condição de vida da população da área de abrangência na identificação de situações que demandam atenção em saúde mental." (Dalla Vecchia \& Martins, 2009, p. 188). Ainda assim, existe o risco de naturalizar as circunstâncias envolvidas na constituição do processo saúde-doença, muitas vezes consideradas pelos profissionais como eternas e imutáveis, com afirmam Dalla Vecchia \& Martins (2009).

Por outro lado, em uma Unidade Básica de Saúde da cidade de São Paulo, uma análise de entrevistas realizadas com médicos pediatras mostrou um discurso que incluía a consideração do meio ambiente na configuração do sofrimento mental da criança, o que foi considerado um passo importante na potencialização da equipe. (Tanaka \& Ribeiro, 2009).

Uma investigação realizada em uma unidade de saúde mista do município do Rio de Janeiro encontrou a prevalência do modelo biomédico no arcabouço explicativo dos profissionais acerca do processo de adoecimento psíquico. Alguns relatos trazem uma compreensão mais ampla, que engloba a presença de determinantes sociais no aparecimento do transtorno; entretanto, "uma concepção de problema de saúde mental enquanto desvio da norma também está fortemente presente no discurso dos profissionais e técnicos de saúde." (Silveira \& Vieira, 2009, p. 145).

Figueiredo e Rodrigues (2004), em investigação sobre as práticas de psicólogos nos CAPSs do Estado do Espírito Santo, encontraram entre os profissionais concepções que pouco remetiam às relações sociais nas quais estes últimos se encontravam inseridos. Apenas uma das respostas analisadas abordou a doença como algo que interfere no exercício de cidadania do usuário.
A supressão do contexto social no arcabouço explicativo da doença também foi percebida nos discursos de profissionais do CAPS de Andradas, Minas Gerais (Antunes \& Queiroz, 2007). Nesta pesquisa, em que todos os profissionais da saúde da equipe do estabelecimento foram entrevistados, encontrouse uma tendência a explicar a doença a partir de uma base organicista, embora também tenha sido considerada a esfera emocional. Assim, as concepções não levaram em conta o contexto como facilitador da constituição do estado patológico, reduzindo-se a uma "reificação do paciente". "Nesse sentido, o processo saúdedoença torna-se impregnado pelos preceitos que concebem a doença como o resultado da perturbação da regularidade e do equilíbrio biológico." (Antunes \& Queiroz, 2007, p. 210).

No CAPS da cidade de São Carlos, no Estado de São Paulo, de maneira semelhante, as crises foram atribuídas pelos profissionais de saúde "ao descontrole, ... à insatisfação de alguma necessidade, como a de ser ouvido ..., e a solução estaria também pautada nas reflexões e direcionamento impulsionado pela vontade." (Leão \& Barros, 2008, p. 103).

Em um CAPS de Salvador, Bahia, os profissionais de nível superior da instituição levam em conta as necessidades sociais dos usuários; porém muitos deles ainda separam o que seria da ordem da psicopatologia e o que seria da ordem do social (Nunes, Torrenté, Ottoni, Moraes Neto \& Santana, 2008), dicotomizando os processos de saúde e doença.

Um estudo realizado na rede pública de Saúde da cidade de Campina Grande, Paraíba, com profissionais inseridos nos CAPS's e com profissionais que atuavam em hospital psiquiátrico, investigando as representações sociais da doença mental, obteve como resultado a forte presença de uma concepção organicista, principalmente no âmbito hospitalar. Nos serviços substitutivos apareceram representações mais fluidas, porém também com uma inclinação a uma suposta predisposição genética como compreensão. Nos discursos sobre normalidade/ anormalidade, falou-se da dificuldade de se delimitar o que seria "normal". A maior parte das representações colhidas na rede substitutiva associou a normalidade à possibilidade de 0 indivíduo conviver em harmonia com a sociedade ou com os diversos grupos, enquanto uma parcela menor dos entrevistados (quase todos do âmbito 
hospitalar) associou a normalidade a um suposto controle de emoções e ações, à aceitação de um suposto limite e à necessidade de que o indivíduo se perceba como diferente. Quanto à noção de periculosidade, "o medo se apresentou de maneira mais generalizada apenas no âmbito hospitalar" (Leite, 2012, p. 26).

De modo geral, os estudos que envolvem o CAPSi são escassos (Cunha \& Boarini, 2011). Não foram encontrados na literatura trabalhos que buscassem conhecer a concepção de profissionais sobre os processos de adoecimento de crianças e adolescentes atendidos no CAPSi, o que justifica a iniciativa desta pesquisa. Em nosso estudo tivemos como objetivo investigar as concepções dos processos de saúde e doença mental dos profissionais que atuam em um CAPSi de uma cidade da Região Sudeste do Brasil. Com os resultados, pretendemos contribuir para a implementação de políticas públicas de assistência no âmbito da saúde mental infanto-juvenil.

\section{MÉTODO}

\section{Participantes}

Participaram do estudo os profissionais que atuavam em um CAPSi de uma cidade da Região Sudeste do Brasil entre outubro e dezembro de 2009, com exceção de um funcionário, que se recusou a participar, o que não prejudicou a análise dos dados.

Optamos por entrevistar individualmente todos os profissionais da instituição, que totalizavam vinte e quatro, a saber: três médicos (dois psiquiatras e um pediatra), quatro psicólogos (uma funcionária deste grupo a diretora da instituição), dois arteterapeutas, um musicoterapeuta, um terapeuta ocupacional, um técnico esportivo, um assistente social, dois enfermeiros, quatro técnicos de enfermagem, dois assistentes administrativos, dois auxiliares de serviços gerais $E$ um vigilante.

\section{Procedimento de coleta de dados}

Após aprovação do comitê de Ética em Pesquisa e da Secretaria Municipal de Saúde, foi feito um primeiro contato com a diretora da instituição para esclarecimentos gerais a respeito da pesquisa. Em seguida, foi agendada uma reunião com todos os funcionários do CAPSi para apresentação da proposta, na qual os profissionais mostraram-se receptivos à realização do estudo. As entrevistas foram agendadas individualmente, mediante contato da pesquisadora com cada um dos participantes, de acordo com sua disponibilidade. Cada entrevista teve duração aproximada de uma hora. Todas elas foram gravadas e posteriormente transcritas. Todos os participantes assinaram um Termo de Consentimento Livre e Esclarecido, em atendimento à Resolução $n^{\circ}$ 196/196 do Conselho Nacional de Saúde. O instrumento utilizado foi um roteiro de entrevista semiestruturado.

\section{Análise dos dados}

O estudo é de abordagem prioritariamente qualitativa. Esta abordagem "aprofunda-se no mundo dos significados das ações e relações humanas, um lado não perceptível e não captável em equações, médias e estatísticas." (Minayo, 1994, p. 22).

Os dados foram submetidos a uma análise de conteúdo temática (Bardin, 1979). Esta análise, segundo Bardin (1979), "consiste em descobrir os 'núcleos de sentido' que compõem a comunicação, e cuja presença ou frequência de aparição pode significar alguma coisa para o objetivo analítico escolhido." (p. 105).

Em nosso estudo construímos categorias, o que significa agregar ideias, elementos e expressões em um "conceito" que os abarque (Minayo, 1994). Assim, organizamos as categorias temáticas que emergiram da análise em um grande tema geral, estipulado previamente, a saber: concepções dos processos de saúde e doença. Entendemos por concepções dos processos de saúde e doença a forma como os profissionais compreendem os transtornos mentais vivenciados pelas crianças $\mathrm{e}$ adolescentes do CAPSi.

Todos os temas categorizados serão apresentados e discutidos à luz da literatura e, a seguir, ilustrados por alguns trechos das falas dos profissionais. Estes serão identificados pela letra $E$ seguida de um número, representando os entrevistados (E1, E2, E3, etc.). Os temas se encontram organizados por ordem de frequência, iniciando-se pelo que mais se repetiu nos discursos dos profissionais. Ressaltamos que nesta análise os profissionais podem ter participação em mais de um tema e que não surgiram temas específicos a uma determinada categoria profissional. Também esclarecemos que a análise das entrevistas não contemplou 
apenas uma categoria ou segmento profissional. Nesses termos, todos os funcionários que trabalhavam na instituição pesquisada à época do estudo foram entrevistados, com exceção de um único funcionário, como já foi mencionado. Esta opção metodológica se deu em função do próprio funcionamento do CAPSi, que se propõe ser interdisciplinar, e pelo fato de que todos os entrevistados entravam em contato diariamente com a clientela atendida, produzindo efeitos com seus diversos olhares sobre este público.

\section{RESULTADOS E DISCUSSÃO}

Os profissionais entrevistados apresentam diferentes explicações para os processos de saúde e doença mental de crianças e adolescentes.

Um primeiro conjunto de resultados aponta a explicação multicausal, que considera a presença de vários fatores constitutivos do transtorno mental. Dentre os entrevistados, dezessete buscam explicar o transtorno mental das crianças e adolescentes levando em consideração a presença de fatores de ordem social, econômica e familiar na constituição do transtorno:

não quer dizer que seja só na família, no núcleo principal, né? Às vezes tem também mais leve, mas tem essa história mais intensa na família. Histórias de drogadição, alcoolismo, e... então tem... quase sempre, se a gente faz um levantamento, quase sempre você tem um, dois, três fatores contribuindo aí ( $\mathrm{E}$ 06).

Esse tema ganhou relevância entre os profissionais. Lançando mão de fatores variados para explicar o fenômeno "transtorno mental", os profissionais parecem romper com a concepção monocausal e determinista, aproximando-se do argumento de Canguilhem (1943), segundo o qual o estado patológico envolve a troca do indivíduo com um meio mais limitado. Este meio, segundo o autor, impossibilita o doente de apresentar as mesmas respostas exigidas por um meio saudável. Nesses termos, um transtorno mental é tido como uma reação patológica a fatores que incluem um contexto, e não como um fenômeno predefinido, ou predeterminado.

\section{Transtorno da esfera do relacionamento}

Outro tema que ganhou destaque entre os profissionais foi a ênfase no aspecto relacional dos transtornos vivenciados pelas crianças e adolescentes. Dos vinte e quatro profissionais entrevistados, quinze abordaram tais fenômenos como uma dificuldade do indivíduo em situar-se no mundo ou de conviver com o outro:

uma tristeza profunda, uma ansiedade,
uma agressividade... de alguma forma o
incapacita pras relações na vida... Então
é um tipo de sentimento ou sensação
que faz com que esse sujeito ele não
tenha uma vida social, que ele tenha um
grau de isolamento; ou, por exemplo, no
caso da criança, é muito comum que a
rede dela seja rompida. Então ela não
frequenta escola, ela não frequenta
parques, ela fica em casa (E 07).

O destaque dado a este aspecto faz referência ao tema apresentado anteriormente, em que o transtorno é visto como decorrente da conjunção de variados fatores, sociais e familiares, constituindo-se de maneira contextualizada. Para Canguilhem (1943), não é possível conceber a existência de um transtorno "em si", pois todo e qualquer estado patológico se dá em uma relação.

A consideração de elementos relacionais no transtorno mental sinaliza as possibilidades de intervenção que levem em conta todas as conjunções que fazem parte do meio no qual a criança e o adolescente estão inseridos. As falas dos profissionais convergem para as ideias de Canguilhem (1943), segundo as quais o normal é sempre singular.

\section{Transtorno mental e risco}

O transtorno mental aparece repetidamente nas entrevistas associado ao risco, seja ele social ou de iminência de morte propriamente dita. Dez profissionais mencionam o elemento "risco" relacionando-o muitas vezes à gravidade do transtorno:

ser preso e tudo mais, ele tava se
colocando em risco em função desse
quadro mental confuso, né, isso é um
caso grave - tá entendendo? - onde o
sujeito não tem condições, ele não tem
condições de, por si, conduzir a própria
vida, né, e as vozes às vezes davam
comandos a ele pra fazer coisas, né... de
xingar, de bater, de jogar pedra, de 
buscar aquilo, né? Então quer dizer, era um quadro que requer um acolhimento e uma contenção muito grande (E 18).

Os entrevistados citam fatores variados - de ordem social, econômica, etc. - como agravantes ou facilitadores da formação de um transtorno, em semelhança ao que foi apresentado na primeira categoria temática; mas citam também que o próprio transtorno, já constituído, induz ao risco. "Nesse sentido, o efeito cumulativo das iniquidades na saúde mental é observado pelo gradiente de risco que se associa à precarização da competência social e à presença de problemas de comportamentos de crianças." (Assis, Avancini \& Oliveira, 2009, p. 98). Caponi (1997) afirma, em contraponto, que a saúde envolve certo grau de abertura ao risco, embora ressalte condições desfavoráveis que muitas vezes prescindem da possibilidade de escolha, como a distribuição desigual da riqueza, condições desfavoráveis de trabalho e outras precariedades sociais.

\section{O transtorno vivenciado como um peso nas famílias das crianças e adolescentes}

Ainda quando buscam caracterizar os transtornos mentais, dez dos vinte e quatro profissionais mencionam a presença de uma forte angústia manifestada pelos pais e/ou cuidadores das crianças e adolescentes. Enfatizam que muitos destes chegam ao serviço sobrecarregados, como que sustentando um "peso", e ansiosos por uma solução: "agora, pela história que a gente tem da saúde mental e da loucura, a gente sabe que há uma certa imposição ali de uma carga, de um peso sobre essa família, sobre essa criança, sobre esse adolescente." (E 19).

Para Saraceno (2001), as intervenções destinadas a amenizar este "peso" advindo da interação entre família e paciente são benéficas não apenas para os familiares, mas também para a própria reabilitação ou para a reinserção do adoecido. Nesses termos, a percepção dos profissionais acerca da dinâmica dos processos de saúde e doença sugere um entendimento do adoecer das crianças que envolve 0 adoecimento de toda a dinâmica familiar, ou das relações familiares.

\section{Possibilidades de saúde e cidadania}

Dez dos vinte e quatro entrevistados apontam possibilidades de mudança para as crianças e adolescentes que frequentam o serviço. Falam de crianças e adolescentes com "potenciais" em relação à saúde e à cidadania, mas não no retorno a um padrão supostamente ideal: "são crianças que têm um potencial muito grande de produzir coisas legais, e eu acredito muito nisso, que elas podem produzir coisas legais, eu invisto muito nisso." (E 01).

Para Coelho e Almeida Filho (1999), o retorno ao normal equivale a retomar uma atividade interrompida:

\begin{abstract}
Uma terapêutica deve respeitar o novo modo de vida instaurado pela doença, não agindo intempestivamente no sentido do retorno ao normal. A vida não conhece a reversibilidade, mas admite reparações (as curas), que são inovações fisiológicas. A cura pode estar mais próxima da doença ou da saúde se, na estabilidade que ela proporciona, encontra-se ausente ou presente a abertura a eventuais modificações (Coelho \& Almeida Filho, 1999, p. 20).
\end{abstract}

Pode-se afirmar que um número significativo de profissionais levou em conta a existência da possibilidades de promover a saúde das crianças e adolescentes da instituição, pois verbalizam enxergar nelas a potência para produzir e realizar atividades diversas. As entrevistas também se mostram em consonância com as afirmações de Saraceno (2001), para quem a reabilitação psicossocial envolve o processo de formação de cidadania do indivíduo.

\section{0 transtorno mental vivenciado como sofrimento psíquico}

O termo "sofrimento psíquico" apareceu em nove das vinte e quatro entrevistas. Este termo aparece como meio de os profissionais caracterizarem e denominarem o transtorno mental. Para este grupo de profissionais, o sofrimento vivenciado pelos usuários é um dos principais critérios a partir dos quais se estruturam as intervenções: "o transtorno mental grave está sempre associado ao sofrimento, né, porque tira toda a autonomia da pessoa, tira as possibilidades, porque o convívio social tá prejudicado, né? Então, é... transtorno mental grave tá ligado a sofrimento psíquico.” (E 06).

Os entrevistados usam o termo "sofrimento psíquico" ou "sofrimento mental grave" em contraponto a uma tendência circunscrita de um diagnóstico fechado em descrições 
psicopatológicas. Mencionam considerar primordialmente a situação em que a criança se encontra, a qual pode acarretar-lhe prejuízos emocionais, uma vez que a descrição clínica, por si mesma, não indica prioridade de intervenção. Saraceno (2001) destaca o caráter de estigmatização e rótulo que tem o diagnóstico, enfatizando-o como instrumento de "controle social".

No CAPSi, conforme os relatos dos profissionais, a condição de uma criança que não apresente um quadro clínico delimitado, mas que vivencie uma situação familiar ou social que a despotencialize para a vida, pode ser tida como mais grave do que a de um paciente que não vivencie tais situações. Estes relatos indicam uma direção contextualizada do diagnóstico que parece levar em conta "as variáveis reais que mudam as vidas reais das pessoas reais." (Saraceno, 2001, p. 83).

A opção por este termo tal qual o descrevem,parece ampliar entre eles o foco de análise dos transtornos mentais. Para Januário e Tafuri (2009), ao se privilegiar a questão do sofrimento do sujeito, evita-se o reducionismo a um quadro patológico no qual a doença fala por si própria.

\section{Transtorno e o sujeito "coisificado"}

Nove entrevistas apontam a necessidade de resgatar nos pacientes atendidos no CAPSi a condição de sujeito que o transtorno lhes subtrai. É recorrente nos entrevistados o relato de que as crianças e adolescentes chegam até o serviço "coisificados", ou seja, sem autonomia quanto à sua própria vida. O estado "coisificado" foi descrito como um dos componentes que se manifestam no transtorno mental:

como já passaram por muitos serviços, é como se a criança não tivesse muita subjetividade ali. É como se ela fosse tratada como "coisa", assim, sabe? Não tem um estímulo à autonomia dessa criança, a perguntar o que que ela quer, a valorizar isso, a valorizar o que que essa criança tá sentindo (E 01).

Ao disponibilizarem a abertura à escuta e expressão da subjetividade dos usuários do serviço, os profissionais rompem com o reducionismo que "coisifica" o adoecido, evitando que este se torne "objeto" de intervenções que reifiquem o lugar da doença.
Akerman (2003), quando denuncia um discurso de "manutenção da ordem" que subjaz às demandas de um serviço público de saúde mental infanto-juvenil de Betim, deixa claro que muitas vezes os serviços destinados a este público acabam por perpetuar o lugar de exclusão em que os usuários do serviço se encontram. Para o autor, a atitude de tomar alguns comportamentos como irregulares equivale a adotar uma postura policial ao delimitar fronteiras entre o que seria normal ou patológico.

Ao perceberem a necessidade de que as crianças e adolescentes sejam retiradas deste lugar de segregação, os entrevistados sinalizam para a construção de ações de promoção de saúde e de autonomia, sem fazer parceria com discursos massificadores que perpetuam a concepção do adoecimento.

\section{Os movimentos do transtorno}

Foi representativo entre os profissionais o entendimento do transtorno como algo em movimento. Nove entrevistas deixam explícita a compreensão de que os transtornos apresentam altos e baixos, em caráter de alternância, tornando-se difícil a distinção entre transtornos mentais leves e graves: "transtornos eu vejo que eles têm movimentações no seu transcorrer. Não é só assim: "esse é grave, sempre grave. Esse é leve, sempre leve". Não. As coisas se transformam, uma coisa que é pequena pode ir degringolando." (E 03).

De acordo com Coelho e Almeida Filho (1999), é possível estabelecer consonâncias entre as falas dos profissionais sobre o transtorno mental e as considerações que o filósofo Canguilhem tece a respeito do normal e do patológico. Concebe-se aqui a não existência de um estado, saudável ou patológico, que seja linear. Fala-se em variações - ou "oscilações", como as denominam os profissionais. Trata-se de variações de normas, já que ser saudável equivaleria a ser capaz de instituir normas diferentes daquelas que regiam a dinâmica de adoecimento.

\section{Transtornos mentais infanto-juvenis: necessidade precoce de intervenção}

Oito das vinte e quatro entrevistas citam a importância de tratar os transtornos mentais antecipadamente para evitar um possível agravamento: " $\mathrm{Eu}$ acho que é privilégio na infância poder fazer um diagnóstico que a 
gente... Pode tratar de muita coisa precocemente, e evitar que se cronifique, o que é mais difícil de fazer no adulto, de resolver no adulto, né?" (E 14).

Embora boa parte das entrevistas ressalte elementos como a "subjetividade", e a "cidadania", este tema sugere a presença sutil de uma concepção preventivista que nos remete ao movimento higienista.

No contexto higienista, este campo de saber ganha legitimidade para impor normas de saúde à sociedade como um todo, normas que estão impregnadas de uma preocupação com a formação física e especialmente moral das crianças. A saúde aparece atrelada a questões de ordem moral. A criança era alvo das ações, visto que se enxergava nelas a possibilidade de um adulto sadio, entendendo-se sadio como ajustado socialmente às normas e valores dominantes (Cunha \& Boarini, 2011).

As colocações dos profissionais nos levam a questionarmos sobre até que ponto as intervenções junto às crianças e adolescentes do serviço poderiam estar influenciadas ainda por esta visão, que carrega uma supervalorização da medicina enquanto reguladora.

Mesmo não sendo esta a concepção predominante entre os profissionais que atuam no serviço, percebemos quão forte ainda se mostra, ainda que de forma não direta, a presença de elementos que reforçam um papel moralizador e normatizador dentro da instituição.

\section{Transtornos mentais: prejuízos a diferentes áreas do desenvolvimento}

Sete dos vinte e quatro profissionais entrevistados falam dos agravos ao desenvolvimento das crianças e adolescentes acarretados pelos transtornos mentais. Um destes assim se manifesta:

Um sofrimento que você não consegue sair dele sozinho, que você, é... tá te dando prejuízo na sua esfera todinha de relacionamento, socialização, de aprendizagem.... O sofrimento psíquico pode baixar a imunidade, sim. A criança tá mais fragilizada. Ela pode adoecer com mais facilidade. (E 06).

Este tema parece ter relação com o tema anterior, em que os entrevistados apontam uma necessidade precoce de intervenção, com a sutil presença de um preventivismo higienista. Elencando os prejuízos causados pelo transtorno, indiretamente os entrevistados relatam a necessidade urgente de evitar agravos, seguindo a mesma lógica da preocupação com intervenções circunscritas à fase da infância.

O Relatório da Organização Mundial da Saúde afirma que, sendo a infância e a adolescência fases do desenvolvimento, tornase complexo traçar delimitações estanques entre fenômenos normais e fenômenos anormais para estes momentos da vida (Organização Mundial da Saúde, 2002). Tendo-se em vista tal peculiaridade, as afirmações dos profissionais sobre $o$ desenvolvimento das crianças e adolescentes nos levam a supor que algumas das ideias preventivistas herdadas da história da psiquiatria podem estar ainda presentes entre suas concepções.

\section{Agressão física e sofrimento mental}

Sete profissionais relatam que as crianças e adolescentes do CAPSi não raro se utilizam da agressão física como forma de expressão do sofrimento psíquico. São relatados episódios de agressão a si próprio e a outrem, com algumas manifestações dentro do próprio CAPSi:

Porque tem muitos pacientes que só conseguem expressar isso por meio da agressividade, né? De autoagressão, de heteroagressão... de xingamento, de... tem outras manifestações. E a gente tenta estimular nesse grupo; então, que isso apareça... que se construa isso de uma outra forma; que se possa falar que tá sentindo raiva, que tá com ódio... que isso possa ser falado, é... falado - e não transformado em atos, né, em ações que vão prejudicar esse paciente (E 01).

Afirma Ribeiro (2008) que, "apesar de muitas vezes a agressividade ser focada na criança e em suas relações familiares, a mesma vem se revelando agressiva num processo de subjetivação no qual todos que estão vinculados a ela, estão diretamente implicados." (p. 13).

A percepção dos profissionais sinaliza para uma intervenção que se constitua como mediadora da expressão do sofrimento por outras vias, que fujam às manifestações de agressão a outrem e de autoagressão.

Este elemento da busca de alternativas mediadoras para as crianças e adolescentes concordam com as colocações anteriores feitas pelos próprios profissionais acerca do caráter 
relacional do adoecimento. A dimensão do vínculo, valorizada entre os profissionais, mostra-se fundamental para os propósitos de socialização e inclusão apontados como pontos focais do CAPSi.

Outras duas categorias temáticas apareceram com menos força nas entrevistas, ambas com frequência de cinco das vinte e quatro entrevistas, mas possuem relevância por divergirem da maioria dos profissionais: são os denominados "Transtornos mentais em si" e "Transtornos mentais sem solução". Os primeiros seriam os transtornos mentais associados a um quadro clínico preestabelecido, sem menção a outros fatores correlacionados; e quanto os segundos, os entrevistados acreditam que $o$ que as crianças e adolescentes apresentam é algo sem solução, como as recaídas do processo e impossibilidade de cura. Vale lembrar que esta concepção, embora não tenha tido destaque no conjunto das entrevistas, deve ser destacada, uma vez que ainda se apresenta como um traço a ser superado para confluir com a proposta do serviço.

\section{CONSIDERAÇÕES FINAIS}

Neste estudo tivemos como objetivo compreender a forma como os profissionais do CAPSi de Vitória (ES) percebem os processos de saúde e doença das crianças e adolescentes atendidos no serviço.

A maior parte dos profissionais explica os transtornos como causados por um conjunto de fatores, principalmente de ordem familiar e social, à semelhança do que fora encontrado no estudo de Dalla Vecchia e Martins (2009) sobre os profissionais de uma equipe de Saúde da Família do Interior do Estado de São Paulo. Os profissionais do CAPSi ressaltam o peso de tais fatores na formação dos estados patológicos, tendendo a considerar primordialmente a situação de sofrimento vivenciada pela criança e inclinandose para um diagnóstico contextualizado. Relatam ainda que compreendem transtornos mentais como fenômenos de caráter relacional, ou seja, como fenômenos que incapacitam ou dificultam o estabelecimento de relações sociais saudáveis.

Esta concepção reforça outra ideia presente entre os profissionais: a de que os transtornos das crianças e adolescentes são vivenciados como um "peso" para suas famílias. Sendo assim, o sofrimento ou adoecimento é visto de maneira ampliada, como algo decorrente de uma dinâmica de relações, e não como uma entidade "em si".

A consideração de tal dinâmica parece influenciar a abertura, percebida por uma parte dos profissionais, dos transtornos mentais para a cidadania e para a reinserção social, semelhantemente às representações sociais encontradas entre profissionais da rede de serviços substitutivos de Campina Grande, Paraíba (Leite, 2012). Os profissionais do CAPSi não se referem aos transtornos garantindo uma "cura" ou um estado "normal" a partir de um modelo predefinido. Falam, sim, em possibilidades de resgate de uma condição diferente da vivenciada no transtorno, em que seja possível a convivência saudável nos espaços oferecido pela sociedade e nas relações sociais em geral.

Os entrevistados ressaltam que os transtornos mentais e sua passagem a um estado "saudável" não acontecem de maneira linear, como um retorno repentino a um estado normal (Coelho \& Almeida Filho, 1999), mas manifestam-se com oscilações, de maneira que uma melhora e uma "recaída" podem suceder-se alternadamente. Estes resultados reforçam, neste estudo, nossa opção por referirmo-nos metodologicamente a tais fenômenos como processos de saúde e doença.

Ademais, é recorrente nas entrevistas a referência ao transtorno como algo que usualmente transpõe a criança ou o adolescente para o lugar de "objeto", seja da família seja das intervenções profissionais nos serviços de cuidado (Akerman, 2003). Ao mesmo tempo, é mencionada a possibilidade de se retirar a criança e o adolescente desta condição, proporcionando-lhes espaço para manifestação da subjetividade.

De modo geral, as ideias que circulam entre os profissionais da instituição parecem incluir o resgate da cidadania e a reinserção dos sujeitos; não obstante, ainda se mostram presentes entre os profissionais alguns elementos que fazem referência a uma condição antecedente ao movimento da Reforma Psiquiátrica.

Ao mencionarem uma necessidade "precoce" de intervenção e os prejuízos que se colocam ao desenvolvimento pleno das crianças e adolescentes, os profissionais deixam transparecer uma visão ainda carregada do preventivismo característico de modelos 
anteriores às propostas que vieram com a Reforma Psiquiátrica. Apesar de não ter sido mencionado pela maioria dos profissionais, este elemento apresenta relevância, uma vez que nos fornece a dimensão ampliada dos avanços e retrocessos do movimento da Reforma.

Além disso, alguns profissionais ainda mencionam o transtorno como um fenômeno descontextualizado, destacando seu caráter nosográfico - como a ele se referem os profissionais do CAPS de Andradas, Minas Gerais (Antunes \& Queiroz, 2007); assim eles delimitam as possibilidades de "solução" e de melhoria para as crianças e adolescentes que vivenciam o transtorno, o que sinaliza a presença de algumas ideias do passado que insistem em permanecer.

Por outro lado, evidenciam-se, entre as ideias que atravessam as falas dos entrevistados, os avanços obtidos a partir da constituição do CAPSi, e uma clara aposta do grupo de profissionais na tentativa de caminhar em direção à Reforma.

Os dados da pesquisa nos permitem afirmar que o campo de atenção às crianças e adolescentes com transtornos mentais apresenta inúmeras particularidades e nuanças, daí, talvez, ainda ser escassa a produção de conhecimento que contemple os CAPSi's em específico. Acreditamos que com este estudo pudemos agregar elementos capazes de subsidiar ações eficazes e condizentes com as transversalidades que compõem o campo de assistência em saúde mental infanto-juvenil,e por outro lado, ressaltamos a necessidade de ampliação de pesquisas neste campo.

\section{REFERÊNCIAS}

Akerman, J. (2003). Estratégias de segregação na infância e adolescência: um recorte sobre o campo da saúde mental. In A. M. C. Guerra, \& N. L. Lima (Eds.), A clínica de crianças com transtornos no desenvolvimento: uma contribuição no campo da Psicanálise e da Saúde Mental (pp. 199- 220). Belo Horizonte: Autêntica; FUMEC.

Antunes, S. M. M. O., \& Queiroz, M. S. (2007). A configuração da reforma psiquiátrica em contexto local no Brasil: uma análise qualitativa. Cadernos de Saúde Pública, 23(1), 207- 215.

Assis, S. G., Avancini, J. Q. \& Oliveira, R. V. C. (2009). Desigualdades socioeconômicas e saúde mental infantil. Revista de Saúde Pública, 43(1), 92-100.

Bardin, L. (1979). Análise de Conteúdo. Lisboa: Edições 70.
Bastos, L. H. C. V. (2003). Ilhas de invenção e solidão: um estudo da atenção à saúde mental para a infância e a adolescência em unidades básicas de saúde em Vitória - ES. Dissertação de Mestrado, Escola Nacional de Saúde Pública, Fundação Oswaldo Cruz, Rio de Janeiro, Brasil.

Boarini, M. L., \& Borges, R. F. (1998). Demanda infantil por serviços de saúde mental: sinal de crise. Estudos de Psicologia, 3(1), 83- 108.

Canguilhem, G. (1943). O normal e o patológico. Rio de Janeiro: Forense Universitária.

Caponi, S. (1997) Georges Canguilhem y el estatuto epistemológico del concepto de salud. História, Ciências, Saúde - Manguinhos, 4(2), 287-307.

Coelho, M. T. A. D. \& Almeida Filho, N. (2002). Conceitos de saúde em discursos contemporâneos de referência científica. História, Ciências, Saúde- Manguinhos, 9(2), 315-333.

Coelho, M. T. A. D., \& Almeida Filho, N. (1999). Normalpatológico, saúde- doença: revisitando Canguilhem. Phisis: revista de saúde coletiva, 9(1), 13- 36.

Couto, M. C. V., Duarte, C. S., \& Delgado, P. G. G. (2008). A saúde mental infantil na Saúde Pública brasileira: situação atual e desafios. Revista Brasileira de Psiquiatria, 30(4), 390- 398.

Cunha, C. C. \& Boarini, M. L. (2011). O lugar da criança e do adolescente na Reforma Psiquiátrica. Revista Psicologia e Saúde, 3(1), 68- 76.

Dalla Vecchia, M. \& Martins, S. T. F. (2009). Concepções dos cuidados em saúde mental por uma equipe de saúde da família, em perspectiva histórico-cultural. Ciência \& Saúde Coletiva, 14(1), 183-193.

Figueiredo, V. V., \& Rodrigues, M. M. P. (2004). Atuação do psicólogo nos CAPS do estado do Espírito Santo. Psicologia em Estudo, 9 (2), 173- 181.

Januário, L. M. \& Tafuri, M. I. (2009) O sofrimento psíquico grave e a clínica com crianças. Revista mal-estar e subjetividade, 9(2), 527-550.

Leão, A., \& Barros, S. (2008). As representações sociais dos profissionais de saúde mental acerca do modelo de atenção e as possibilidades de inclusão social. Saúde e Sociedade, 17(1), 95- 106.

Leite, L. D. G. (2012). Concepções e práticas profissionais relativas à doença mental. Revista Brasileira de Ciências da Saúde, 16(1), 21-28.

Minayo, M. C. S. (1994) Pesquisa social: teoria, método e criatividade. Petrópolis: Vozes.

Nunes, M., Torrenté, M., Ottoni, V., Neto, V. M., \& Santana, M. (2008). A dinâmica do cuidado em saúde mental: signos, significados e práticas de profissionais em um Centro de Atenção Psicossocial em Salvador, Bahia, Brasil. Cadernos de Saúde Pública, 24(1), 188-196.

Organização Mundial da Saúde. (2002). Saúde mental: nova concepção, nova esperança. Lisboa: Climepsi Editores.

Portaria $N^{\circ} 336 / G M$, de 19 de fevereiro de 2002. (2002). Recuperado em 24 de setembro de 2008, de http://portal.saude.gov.br/portal/arquivos/pdf/Portaria $\% 20$ GM\%20336-2002.pdf. 
Resolução No 196, de 10 de outubro de 1996. (1996). Diretrizes e normas regulamentadoras de pesquisas envolvendo seres humanos. Brasília, DF: Ministério da Saúde, Conselho Nacional de Saúde.

Ribeiro, E. C. M. (2008) Crianças que se revelam agressivas: um estudo fenomenológico sobre 0 reconhecimento da agressividade em escolares. Dissertação de Mestrado, Curso de Pós-graduação em Psicologia Clínica e Social, Universidade Federal do Pará, Pará, Brasil.

Saraceno, B. (2001). Libertando identidades: da reabilitação à cidadania possível. Rio de Janeiro: Te Corá.

Silveira, D. P. \& Vieira, A. L. S. (2009). Saúde mental e atenção básica em saúde: análise de uma experiência no nível local. Ciência \& Saúde Coletiva, 14(1), 139-148.
Tanaka, O. Y. \& Ribeiro, E. L. (2009). Ações de saúde mental na atenção básica: caminho para ampliação da integralidade da atenção. Ciência \& Saúde Coletiva, 14(2), 477-486.

Camila Carlos Maia: psicóloga, mestre em Psicologia pelo Programa de Pós- graduação em Psicologia da Universidade Federal do Espírito Santo (2010).

Luziane Zacché Avellar: professora associada II da Universidade Federal do Espírito Santo, no Programa de Pósgraduação em Psicologia e no Departamento de Psicologia Social e do Desenvolvimento. 